\title{
In-Home Rehabilitation Using a Smartphone App Coupled With 3D Printed Functional Objects: Single-Subject Design Study
}

Jeanne Langan ${ }^{1^{*}}, \mathrm{PhD}, \mathrm{PT}$; Sutanuka Bhattacharjya ${ }^{2^{*}}, \mathrm{PhD}$, OTR; Heamchand Subryan ${ }^{3}$, MArch, MFA; Wenyao Xu ${ }^{4}$, $\mathrm{PhD}$; Baicheng Chen ${ }^{4}$; Zhengxiong $\mathrm{Li}^{4}$, MSc; Lora Cavuoto ${ }^{5}$, PhD

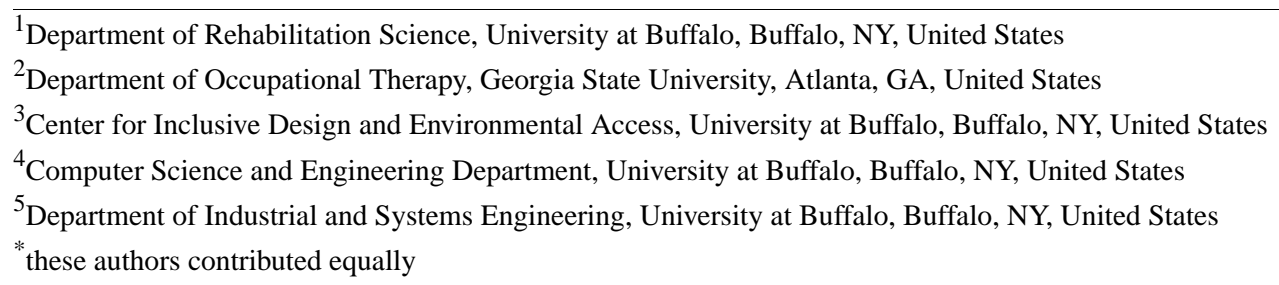

Corresponding Author:

Jeanne Langan, PhD, PT

Department of Rehabilitation Science

University at Buffalo

522 Kimball Tower

3435 Main St

Buffalo, NY, 14214

United States

Phone: 17168292905

Email: jlangan@buffalo.edu

\section{Abstract}

Background: Stroke is a major cause of long-term disability. While there is potential for improvements long after stroke onset, there is little to support functional recovery across the lifespan. mHealth solutions can help fill this gap. mRehab was designed to guide individuals with stroke through a home program and provide performance feedback.

Objective: To examine if individuals with chronic stroke can use mRehab at home to improve upper limb mobility. The secondary objective was to examine if changes in limb mobility transferred to standardized clinical assessments.

Methods: mRehab consists of a smartphone coupled with 3D printed household items: mug, bowl, key, and doorknob. The smartphone custom app guides task-oriented activities and measures both time to complete an activity and quality of movement (smoothness/accuracy). It also provides performance-based feedback to aid the user in self-monitoring their performance. Task-oriented activities were categorized as (1) object transportation, (2) prehensile grip with supination/pronation, (3) fractionated finger movement, and (4) walking with object. A total of 18 individuals with stroke enrolled in the single-subject experimental design study consisting of pretesting, a 6-week mRehab home program, and posttesting. Pre- and posttesting included both in-laboratory clinical assessments and in-home mRehab recorded samples of task performance. During the home program, mRehab recorded performance data. A System Usability Scale assessed user's perception of mRehab.

Results: A total of 16 participants completed the study and their data are presented in the results. The average days of exercise for each mRehab activity ranged from 15.93 to 21.19 days. This level of adherence was sufficient for improvements in time $\left(\mathrm{t}_{15}=2.555, P=.02\right)$ and smoothness $\left(\mathrm{t}_{15}=3.483, P=.003\right)$ in object transportation. Clinical assessments indicated improvements in functional performance $\left(\mathrm{t}_{15}=2.675, P=.02\right)$ and hand dexterity $\left(\mathrm{t}_{15}=2.629, P=.02\right)$. Participant's perception of $\mathrm{mRehab}$ was positive.

Conclusions: Despite heterogeneity in participants' use of mRehab, there were improvements in upper limb mobility. Smartphone-based portable technology can support home rehabilitation programs in chronic conditions such as stroke. The ability to record performance data from home rehabilitation offers new insights into the impact of home programs on outcomes.

Trial Registration: ClinicalTrials.gov NCT04363944; https://clinicaltrials.gov/ct2/show/NCT04363944

(JMIR Mhealth Uhealth 2020;8(7):e19582) doi: $\underline{10.2196 / 19582}$ 


\section{KEYWORDS}

stroke; rehabilitation; smart technology; 3D printing; usability

\section{Introduction}

\section{Background}

Stroke is a major cause of disability, leading to restriction of occupational performance for stroke survivors [1,2]. It is estimated that $30 \%-60 \%$ of stroke survivors continue to have residual limitations in upper extremity movements after traditional rehabilitation services [3]. At the end of rehabilitation services, survivors are commonly given a written home exercise program to guide recovery in chronic stages of stroke [4]. Shortcomings of the written home exercise program include complaints of being unengaging and patients not continuing the program [4]. Knowing that upper limb motor deficits can reduce quality of life [5], it is important to support survivors to recover as much function as possible. Upper limb recovery after stroke is identified as a research priority by survivors of stroke, caregivers, and health professionals [6].

Research demonstrates that individuals with chronic stroke are capable of making gains in performance with continued practice. The research so far has focused on interventions led by therapists $[7,8]$. It is improbable that direct oversight by a therapist is a feasible solution for long-term recovery. For chronic conditions such as stroke, better supporting the individual's ability to self-manage their long-term recovery could offer a more sustainable approach. Use of mHealth (ie, mobile technology to manage health) offers the opportunity for individuals to engage in rehabilitative activities while monitoring their performance and managing their health behaviors $[9,10]$. mHealth apps can assist users in meeting basic needs, thereby giving a sense of autonomy and competence [11]. In addition, participants have reported that it is enjoyable to use apps [12]. Smart devices are equipped with interactive components (eg, sensors, cameras, speakers, and vibrators) capable of measuring human movement and providing feedback [13]. Readily available smartphone technology can be the basis of a home rehabilitation system.
There has been an increase in app development for stroke rehabilitation. A review of apps designed for stroke survivors or their caregivers found that $62 \%$ of apps addressed language or communication [14]. Other apps addressed stroke risk calculation, identifying acute stroke, atrial fibrillation, direction to emergency room or nearest certified stroke center, visual attention therapy, and a mere $4 \%$ addressed physical rehabilitation [14]. Importantly, apps for rehabilitation did not focus on upper limb function [14]. Use of technology to guide and measure performance in task-specific training of the upper extremity after stroke has primarily included clinical or laboratory-based interventions $[15,16]$. Task-specific programs are function based, with practice of tasks relevant to activities of daily life, and have been shown to be efficacious [17,18]. Use of instrumented objects in a laboratory setting has resulted in patients reporting they enjoyed the experience [15]. There has been less research on the use of portable technology for upper limb rehabilitation in a home setting for individuals with chronic arm/hand deficits after stroke.

\section{Previous Work}

mRehab (mobile Rehab) was created to better support in-home upper limb rehabilitation programs (Figure 1) [13]. It incorporates a task-oriented approach and immediate performance-based feedback. Exercise programs that include feedback have resulted in better outcomes compared with programs without feedback $[19,20]$. mRehab consists of 3D printed household objects (a mug, bowl, key, and doorknob) integrated with a smartphone and an app. The app guides participants through practice of activities of daily living, for example, sipping from a mug. It can also consistently measure time to complete an activity and quality of movement (smoothness/accuracy) during the performance of activities of daily living. The system is described in more detail in previous articles that have evaluated it in primarily laboratory-based settings [13,21].

Figure 1. In-home use of mRehab: (A) selecting an activity in mRehab; (B) turning key activity; and (C) vertical mug transfer activity.

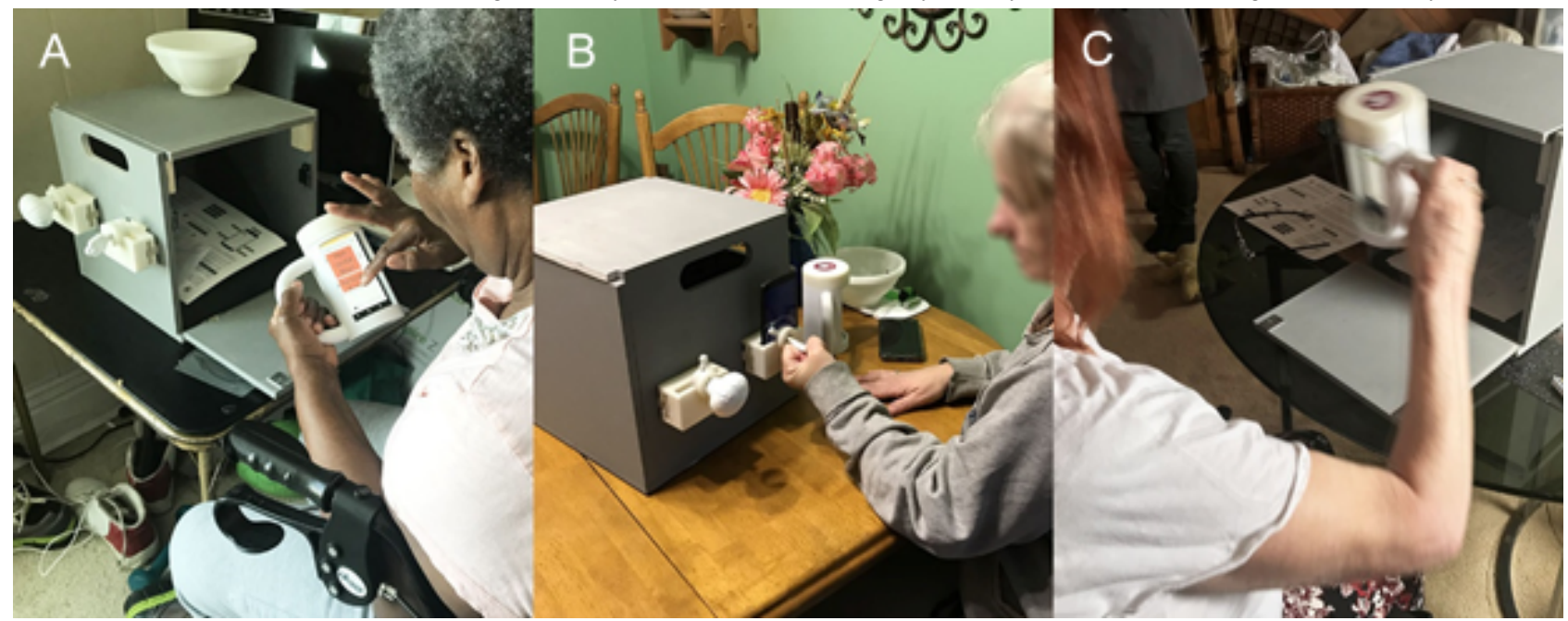


There is little information on in-home use of technology for rehabilitation in chronic stroke. While technology-based systems designed for rehabilitation have been developed, they have typically been examined in laboratory or clinical settings $[22,23]$. The results of this study will provide much needed evidence of the ability of individuals with chronic stroke to use technology in a home-based program with oversight only upon request. This mimics clinical practice, in which patients are discharged from rehabilitation with a home program and then need to self-manage their recovery. We examine the individual's adherence to exercise and if they required support with the technology. The impact of the home-based mRehab program on functional mobility was also examined. While individuals with chronic stroke were selected for the first examination of mRehab in a home-based setting, the system has the potential to be used by individuals that have arm/hand deficits due to other underlying pathology.

\section{Methods}

\section{Participants}

The study was approved by the University at Buffalo Institutional Review Board and all participants provided written informed consent. A total of 18 participants were recruited from the local community. Participants were included if they were (1) at least 18 years of age and living in the community, (2) were 6 or more months after stroke, and (3) had a minimum score of 124 on the Mattis Dementia Rating Scale (MDRS) [24]. Participants were excluded if they met any of the following criteria: (1) acute or chronic pain that would interfere with participation, (2) severely limited range of motion of the upper limb, (3) absent or severely impaired proprioception of the upper limb, (4) musculoskeletal or circulatory conditions affecting the upper limb, (5) spasticity graded as 3 or greater for upper extremity movement on the Modified Ashworth Scale (MAS), or (6) botulinum toxin injections for spasticity management within 3 months of starting the study. These inclusion and exclusion criteria were established to select participants that were likely to have the cognitive and physical capacity to use mRehab.

\section{Design}

A single-subject experimental design with multiple baselines was used. A strength of the single-subject study design is that participants serve as their own control. There is variability in the degree of arm/hand deficits for survivors of stroke, making it challenging to establish an equivalent control group. The single-subject design offers an alternative approach that is commonly used in assessing populations with stroke $[25,26]$. Each participant had a varying length of the baseline and follow-up periods to establish that the intervention, rather than time, was the primary reason for any observed change in performance.

\section{Procedure}

Over a 10-week period, participants completed baseline measurements, a 6-week mRehab home program, and follow-up measurements. Baseline measurements consisted of both in-laboratory and in-home measurements (Figure 2). Participants attended 2 laboratory visits prior to starting the home program. During the first laboratory visit, participants completed a demographic questionnaire and clinical assessments. The Berg Balance Scale (BBS) [27] was used to determine if participants had sufficient balance (score greater than 42) to participate in the walk with mug activity. The Wolf Motor Function Test (WMFT) [28] and Nine-Hole Peg Test [29] were the clinical outcome measures. An occupational therapist demonstrated the mRehab system to the participant. The participant learned to operate the smartphone, mRehab app, and mRehab restricted mode. The mRehab restricted mode was designed to sample baseline in-home performance of 3 representative mRehab activities: horizontal mug transfer, quick twist of the mug, and turn key. Only 3 repetitions of each baseline activity could be performed in a session, for a maximum of 3 sessions per baseline week. Repetitions were limited to avoid improving performance during the baseline period. The app did not give feedback during the restricted mode. At the second laboratory visit, participants completed the same clinical assessments (Figure 2) and learned the remaining 9 mRehab activities for the home program. Participants were instructed to contact the research team if they had questions or concerns. Participant's contacts to the research team were recorded.

Figure 2. mRehab study timeline. BBS: Berg Balance Scale; MAS: Modified Ashworth Scale; MDRS: Mattis Dementia Rating Scale; SUS: Systems Usability Scale; WMFT: Wolf Motor Function Test.

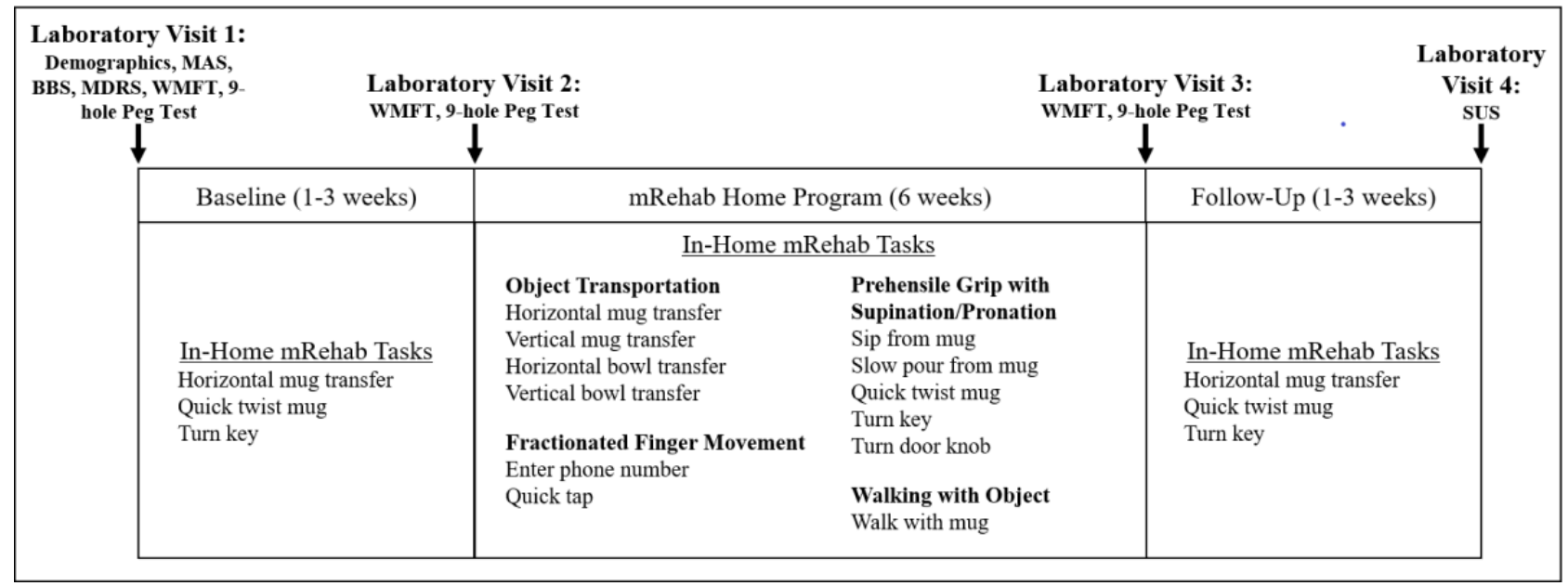


During the home program, participants could select from all 12 mRehab activities (Figure 2). It was suggested that participants complete 10 repetitions of each activity daily, 5 days per week for 6 weeks. The mRehab app recorded and provided feedback (both visual and auditory) on the user's performance (repetitions, time to complete, and smoothness/accuracy) at the end of each activity.

The follow-up phase was similar to the baseline phase (Figure 2 ). The third laboratory visit examined changes in performance of the clinical assessments immediately after the completion of the mRehab home program. Between the third and fourth laboratory visit, participants again used mRehab in the restricted mode without feedback to sample in-home performance. At the fourth laboratory visit, participants returned the 3D printed objects and completed the Systems Usability Scale (SUS) [30]. SUS allows for subjective assessment of perceived usability. Participants responded to 10 questions using a Likert 1-5 scale ( 1 =strongly disagree and 5=strongly agree). Percentile rank out of a possible 100 was calculated.

\section{Statistical Analyses}

\section{mRehab Data}

Performance was examined on each mRehab task and on composites of similar activities: (1) object transportation (horizontal and vertical mug and bowl transfers); (2) prehensile grip with supination/pronation (sip from mug, slowly pour water from mug, quick twist of the mug, turn key, and turn door knob); (3) fractionated finger movement (entering phone number and quick tap); and (4) walking with object activity (here, walk with mug was left out of the analyses because not all participants could perform this activity). The composite score represented the average time to complete the activities in a category.

$\mathrm{mRehab}$ data were examined at both individual and group levels. As is typical with single-subject designs, visual inspection of individual's data was used as the first stage of analysis of adherence and performance change during the intervention. Quantitative changes in motor performance based on mRehab data were examined using paired $t$ tests for the following comparisons: (1) baseline compared with follow-up using the average time to complete and smoothness of each activity, (2) first compared with last training day in the 6-week home program using the average time to complete and smoothness of each activity, and (3) first compared with last training day using composite scores. To examine an a priori hypothesis that the amount of training impacts outcome, correlations between the total number of repetitions performed for each activity during the 6-week home program and changes in performance for each activity were examined.

\section{Clinical Assessments}

Changes in clinical assessments were examined using paired $t$ tests. The average time for tasks in the WMFT was used in the analyses [31]. To meet the normality assumption, the log transform of the average WMFT score was used for the statistical analysis. For both the WMFT and the Nine-Hole Peg Test, the scores from the first and second in-laboratory visits were averaged (scores were not different $[P>.05]$ ) to account for variability in the performance of individuals with stroke. This averaged preintervention score was compared with the third in-laboratory visit to assess the immediate change in performance following use of mRehab. Because some of the mRehab activities resemble tasks in the WMFT, we examined changes for each task in the WMFT to assess if we were in essence training for the clinical test. Significance for all tests was set at $P<.05$.

\section{Usability}

Perceived usability of mRehab was examined. The range and the average of the SUS percentile rank scores were reported. The full assessment of usability including qualitative assessments is beyond the scope of this paper and will be reported in another paper.

\section{Results}

\section{In-Home Use of mRehab}

A total of 18 participants with stroke were recruited from the community (Table 1); 2 participants did not complete the study: 1 participant reported being unable to use mRehab without caregiver assistance and did not wish to continue the home program, whereas the other completed only the first in-laboratory visit and decided he did not have sufficient time in his schedule to complete the full study. The performance data of the remaining 16 participants are reported in the results.

During in-home use of mRehab, 10 participants contacted the research team reporting difficulties with the system. Home visits were made to 7 participants. The most common reason for a home visit was to replace the 3D printed door knob or key or both. The construction of these objects was modified during the study to improve durability. Changing the direction of fill in the $3 \mathrm{D}$ printing process improved the product. A full report on usability will be discussed in detail in another paper. 
Table 1. Participant demographics.

\begin{tabular}{|c|c|c|c|c|c|c|c|c|}
\hline Participant code & Age & Gender & $\begin{array}{l}\text { Years after } \\
\text { stroke }\end{array}$ & Paretic side & $\begin{array}{l}\text { Reported } \\
\text { dominant arm }\end{array}$ & $\begin{array}{l}\text { Reported dominant } \\
\text { arm prior to stroke }\end{array}$ & $\mathrm{MDRS}^{\mathrm{a}}$ & $\mathrm{WMFT}^{\mathrm{b}}(\mathrm{s})^{\mathrm{c}}$ \\
\hline $\mathrm{s} 01^{\mathrm{d}}$ & 57 & F & 2 & $\mathrm{R}$ & $\mathrm{L}$ & $\mathrm{R}$ & 132 & 43.10 \\
\hline s02 & 54 & F & 7 & $\mathrm{~L}$ & $\mathrm{R}$ & $\mathrm{L}$ & 144 & 4.84 \\
\hline $\mathrm{s} 03$ & 68 & M & 4 & $\mathrm{R}$ & $\mathrm{L}$ & $\mathrm{R}$ & 142 & 13.78 \\
\hline s04 & 61 & $\mathrm{~F}$ & 12 & $\mathrm{R}$ & $\mathrm{L}$ & $\mathrm{R}$ & 140 & 10.12 \\
\hline s05 & 78 & $\mathrm{~F}$ & 1 & $\mathrm{~L}$ & $\mathrm{R}$ & $\mathrm{R}$ & 140 & 4.75 \\
\hline s06 & 66 & M & 14 & $\mathrm{~L}$ & $\mathrm{R}$ & $\mathrm{L}$ & 140 & 44.77 \\
\hline s07 & 73 & M & 1 & $\mathrm{~L}$ & $\mathrm{R}$ & $\mathrm{L}$ & 139 & 39.37 \\
\hline s08 & 61 & M & 0.5 & $\mathrm{~L}$ & $\mathrm{R}$ & $\mathrm{R}$ & 142 & 1.85 \\
\hline s09 & 62 & $\mathrm{~F}$ & 2 & $\mathrm{R}$ & $\mathrm{L}$ & $\mathrm{R}$ & 124 & 23.96 \\
\hline s10 & 67 & M & 1 & $\mathrm{R}$ & $\mathrm{L}$ & $\mathrm{R}$ & 130 & 8.65 \\
\hline s11 & 76 & M & 6 & $\mathrm{R}$ & $\mathrm{L}$ & $\mathrm{R}$ & 133 & 2.25 \\
\hline $\mathrm{s} 12$ & 43 & M & 5 & $\mathrm{R}$ & $\mathrm{R}$ & $\mathrm{R}$ & 143 & 2.95 \\
\hline s13 & 76 & M & 4 & $\mathrm{R}$ & $\mathrm{R}$ & $\mathrm{L}$ & 144 & 2.06 \\
\hline s14 & 39 & $\mathrm{~F}$ & 4 & $\mathrm{R}$ & $\mathrm{L}$ & $\mathrm{R}$ & 143 & 2.43 \\
\hline s15 & 78 & M & 3 & $\mathrm{~L}$ & $\mathrm{R}$ & $\mathrm{R}$ & 134 & 34.00 \\
\hline $\mathrm{s} 16^{\mathrm{d}}$ & 56 & M & 6 & $\mathrm{~L}$ & $\mathrm{R}$ & $\mathrm{L}$ & 143 & $80.55^{\mathrm{e}}$ \\
\hline s17 & 72 & M & 11 & $\mathrm{R}$ & $\mathrm{L}$ & $\mathrm{R}$ & 142 & 81.12 \\
\hline s18 & 37 & M & 1 & CL & $\mathrm{R}$ & $\mathrm{R}$ & 141 & 4.95 \\
\hline
\end{tabular}

${ }^{\mathrm{a}}$ MDRS: Mattis Dementia Rating Scale.

${ }^{\mathrm{b}}$ WMFT: Wolf Motor Function Test.

${ }^{\mathrm{c}}$ Average visits 1 and 2 .

${ }^{\mathrm{d}}$ Indicates participant did not complete the study.

${ }^{\mathrm{e}}$ Participant only completed visit 1 .

\section{mRehab In-Home Recorded Data}

Visual analyses of individual data show differences between participants in adherence and performance of the mRehab activities. As an example, Figure 3 shows individual data sets for the time to complete the activity horizontal mug transfer during the baseline, 6-week program, and follow-up. Participants demonstrated variance in the number of days exercised, the rate of performance change, and the stability of performance. The majority of participants reduced their time to complete the horizontal mug transfer by the end of the 6-week program.

Quantitative changes in mRehab performance were examined. Baseline and follow-up data were compared for horizontal mug transfer and key turn. The quick twist of the mug data were excluded from analysis because only few participants could twist quickly enough for the sensor to capture the movement. Participants demonstrated a decrease in time from baseline to follow-up in the horizontal mug transfer $\left(\mathrm{t}_{15}=2.14, P=.05\right.$; Figure
$4)$, and the decrease for key turn $\left(\mathrm{t}_{15}=1.86, P=.08\right)$ approached the commonly accepted $\alpha .05$ level (Figure 5). Comparing performance on the first day of training with the last training day in the 6-week program (Table 2), there was a trend across activities for improved scores in both time and smoothness at the last session. All object transportation activities and quick tap, a fractionated finger movement activity, reduced in time to complete. On the last day of the program, vertical and horizontal mug transfer were performed more smoothly and quick tap more accurately. No correlation examining the number of repetitions completed during the home program and changes in performance of an activity (time to complete or smoothness) resulted in $P$ values <.05. Comparing composite scores from the first and last day of training, object transportation improved in time $\left(\mathrm{t}_{15}=2.555, P=.02\right.$; Figure 5$)$. Neither the composite score for prehensile grip with supination/pronation nor fractionated finger movement demonstrated significant improvement in time (Figure 5). 
Figure 3. Data sets from 16 participants showing their performance on horizontal mug transfer during baseline, 6-week home program, and follow-up. The number of days they did this activity is on the $\mathrm{x}$ axis. Asterisk $\left(^{*}\right)$ indicates the average time to complete horizontal mug transfer on that day was above 10 seconds.

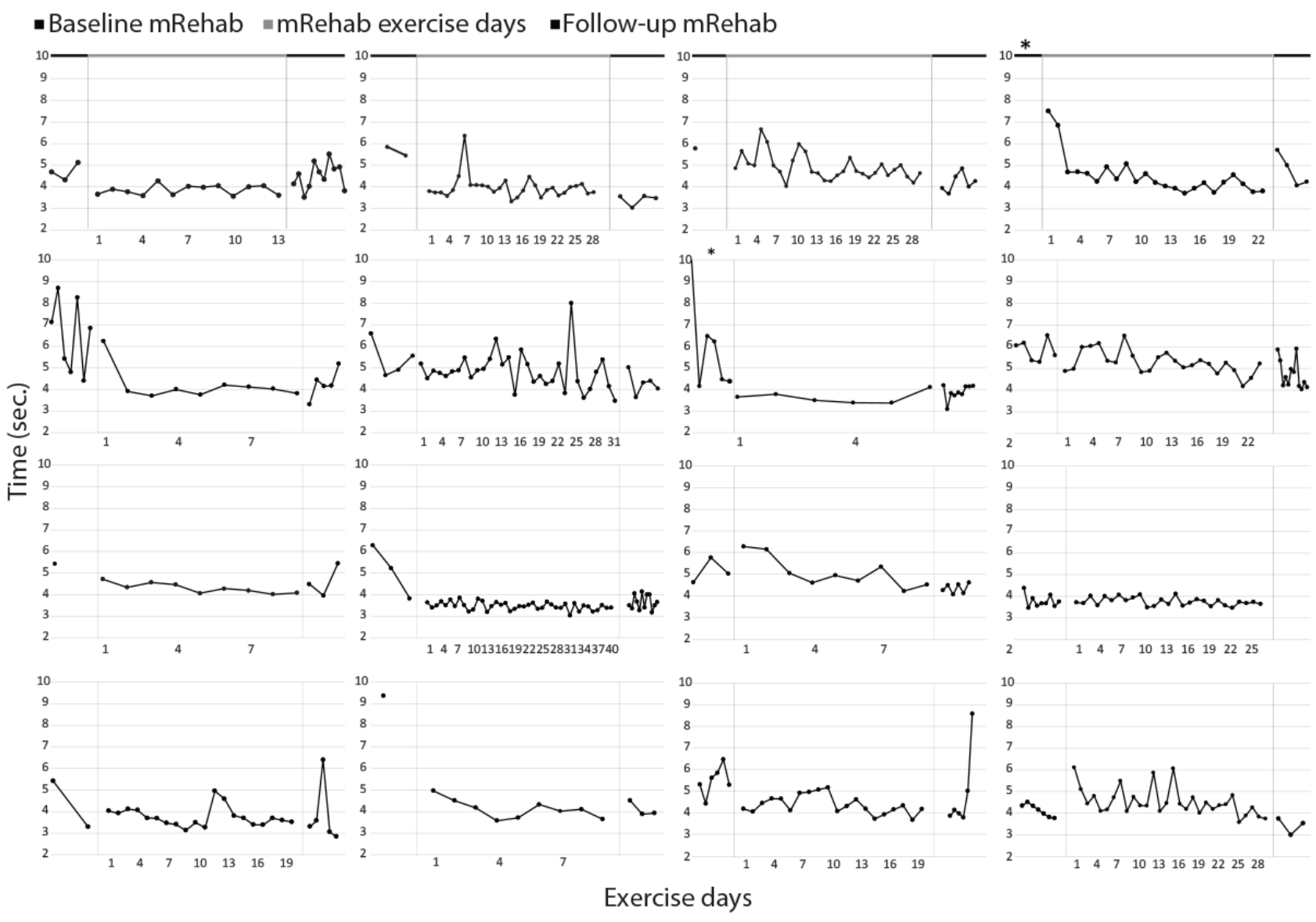

Figure 4. Pre- and postintervention average time to complete horizontal mug transfer and turning a key. $*$ indicates a $P$ value $<.05$.

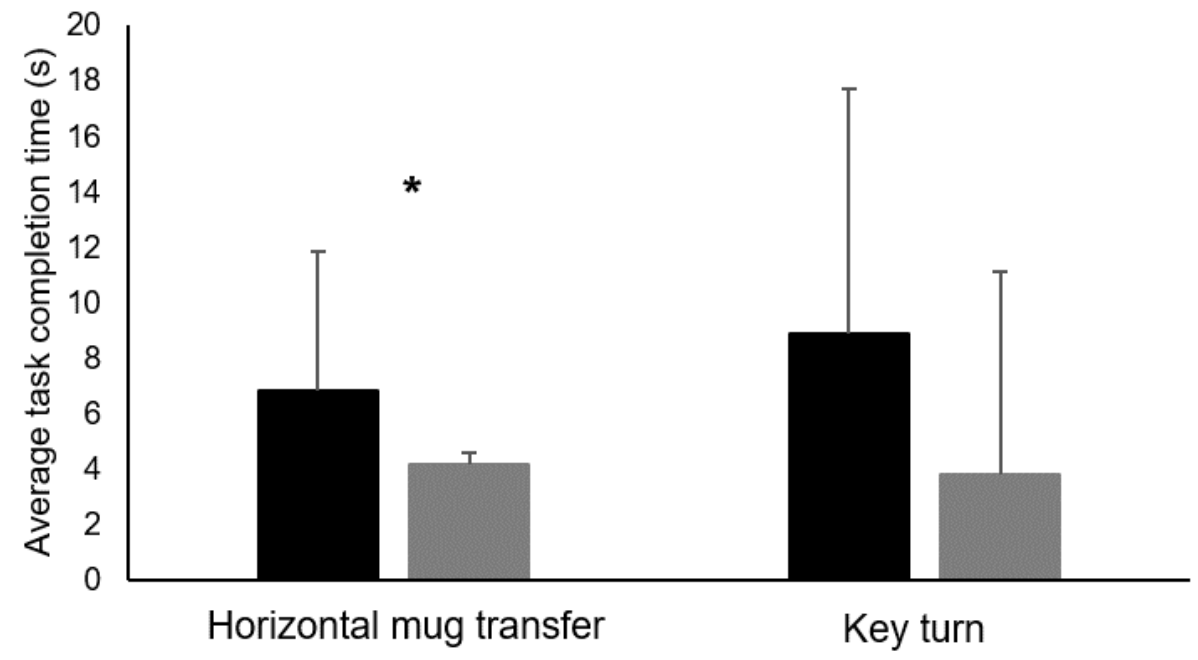

- Baseline time Follow-up time 
Figure 5. Start and end of intervention average time to complete task for composite task groupings. Error bars represent standard deviations. * indicates a $P$ value $<.05$.

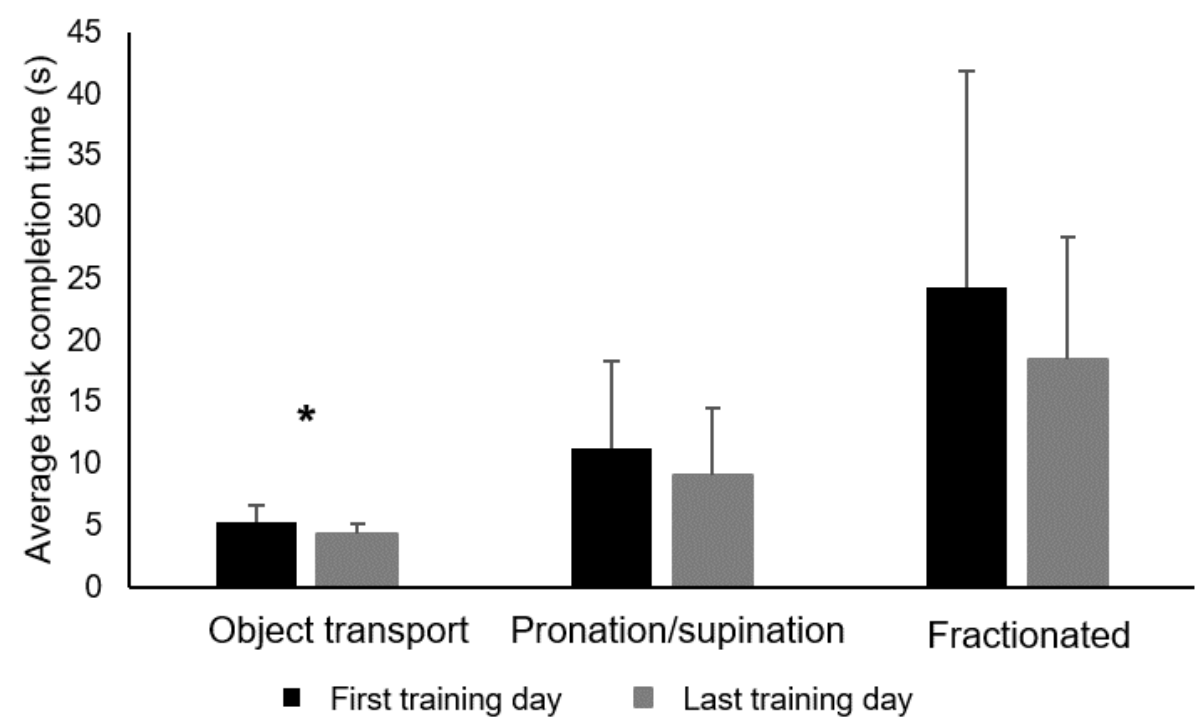


Table 2. Group data performance changes on each activity in mRehab.

\begin{tabular}{|c|c|c|c|c|c|c|c|c|c|}
\hline Activity & $\mathrm{N}$ & $\begin{array}{l}\text { Number of ex- } \\
\text { ercise days, } \\
\text { mean (SD) }\end{array}$ & $\begin{array}{l}\text { Total number } \\
\text { of repetitions, } \\
\text { mean (SD) }\end{array}$ & $\begin{array}{l}\text { First session } \\
\text { time, mean } \\
\text { (SD) }\end{array}$ & $\begin{array}{l}\text { Last session } \\
\text { time, mean } \\
\text { (SD) }\end{array}$ & $\begin{array}{l}P \text { value (for } \\
\text { last session } \\
\text { time) }\end{array}$ & $\begin{array}{l}\text { First session } \\
\text { smoothness, } \\
\text { mean (SD) }\end{array}$ & $\begin{array}{l}\text { Last session } \\
\text { smoothness, } \\
\text { mean (SD) }\end{array}$ & $\begin{array}{l}P \text { value (for } \\
\text { last session } \\
\text { smoothness) }\end{array}$ \\
\hline \multicolumn{10}{|c|}{ Object transportation } \\
\hline $\begin{array}{l}\text { Vertical bowl } \\
\text { transfer }\end{array}$ & 16 & $20.75(10.60)$ & $\begin{array}{l}282.06 \\
(210.00)\end{array}$ & $5.04(0.91)$ & $4.03(0.46)$ & $<.001$ & $\begin{array}{l}511.99 \\
(297.33)\end{array}$ & $\begin{array}{l}410.66 \\
(128.81)\end{array}$ & $-^{\mathrm{a}}$ \\
\hline $\begin{array}{l}\text { Horizontal } \\
\text { bowl transfer }\end{array}$ & 16 & $20.88(10.64)$ & $\begin{array}{l}289.44 \\
(223.34)\end{array}$ & $5.03(1.32)$ & $4.01(0.60)$ & .001 & $\begin{array}{l}478.53 \\
(315.49)\end{array}$ & $\begin{array}{l}375.39 \\
(137.23)\end{array}$ & - \\
\hline $\begin{array}{l}\text { Vertical mug } \\
\text { transfer }\end{array}$ & 16 & $21.06(10.64)$ & $\begin{array}{l}283.69 \\
(227.94)\end{array}$ & $5.22(1.22)$ & $4.19(0.55)$ & .003 & $\begin{array}{l}699.24 \\
(321.74)\end{array}$ & $\begin{array}{l}492.70 \\
(226.60)\end{array}$ & .02 \\
\hline $\begin{array}{l}\text { Horizontal } \\
\text { mug transfer }\end{array}$ & 16 & $21.19(10.62)$ & $\begin{array}{l}292.31 \\
(224.02)\end{array}$ & $4.96(1.22)$ & $4.00(0.58)$ & .009 & $\begin{array}{l}585.83 \\
(233.81)\end{array}$ & $\begin{array}{l}431.23 \\
(159.97)\end{array}$ & .04 \\
\hline \multicolumn{10}{|c|}{ Prehensile grip with supination/pronation } \\
\hline Sip from mug & 16 & $20.00(10.81)$ & $\begin{array}{l}202.19 \\
(151.48)\end{array}$ & $9.51(4.71)$ & $9.62(1.39)$ & - & $\begin{array}{l}394.17 \\
(239.46)\end{array}$ & $\begin{array}{l}331.11 \\
(61.77)\end{array}$ & - \\
\hline $\begin{array}{l}\text { Slow pour } \\
\text { with mug }\end{array}$ & 15 & $20.06(10.24)$ & $\begin{array}{l}148.94 \\
(137.23)\end{array}$ & $25.07(8.58)$ & $20.69(4.08)$ & .06 & $\begin{array}{l}807.39 \\
(323.21)\end{array}$ & $\begin{array}{l}655.29 \\
(249.62)\end{array}$ & .048 \\
\hline $\begin{array}{l}\text { Quick twist } \\
\text { mug }\end{array}$ & 14 & $18.36(12.53)$ & $\begin{array}{l}228.29 \\
(195.81)\end{array}$ & $4.30(5.24)$ & $3.34(5.28)$ & - & $\begin{array}{l}747.08 \\
(1394.73)\end{array}$ & $\begin{array}{l}532.92 \\
(1125.29)\end{array}$ & .07 \\
\hline Turning a key & 14 & $15.93(11.01)$ & $\begin{array}{l}177.20 \\
(141.26)\end{array}$ & $6.03(5.48)$ & $4.48(7.32)$ & - & $\begin{array}{l}41.17 \\
(33.28)\end{array}$ & $\begin{array}{l}42.53 \\
(65.15)\end{array}$ & - \\
\hline $\begin{array}{l}\text { Turning a } \\
\text { doorknob }\end{array}$ & 15 & $18.81(11.00)$ & $\begin{array}{l}199.13 \\
(139.04)\end{array}$ & $6.65(10.75)$ & $2.21(1.53)$ & - & $\begin{array}{l}33.58 \\
(32.05)\end{array}$ & $\begin{array}{l}31.76^{\mathrm{b}} \\
(38.02)\end{array}$ & - \\
\hline \multicolumn{10}{|c|}{ Fractionated finger movement } \\
\hline $\begin{array}{l}\text { Enter phone } \\
\text { number }\end{array}$ & 16 & $19.13(10.00)$ & $\begin{array}{l}153.13 \\
(131.05)\end{array}$ & $\begin{array}{l}30.86 \\
(26.28)\end{array}$ & $\begin{array}{l}22.35 \\
(14.05)\end{array}$ & - & $\mathrm{NA}^{\mathrm{c}}$ & NA & - \\
\hline Quick tap & 16 & $19.38(10.33)$ & $\begin{array}{l}177.20 \\
(141.26)\end{array}$ & $17.05(9.42)$ & $14.75(7.54)$ & .005 & NA & NA & - \\
\hline \multicolumn{10}{|c|}{ Walking with object } \\
\hline $\begin{array}{l}\text { Walk with } \\
\text { mug }\end{array}$ & 11 & $16.87(12.48)$ & $\begin{array}{l}183.07 \\
(178.70)\end{array}$ & NA & NA & - & $\begin{array}{l}967.42 \\
(99.42)\end{array}$ & $\begin{array}{l}997.98 \\
(77.81)\end{array}$ & - \\
\hline
\end{tabular}

${ }^{\mathrm{a}}$ Not applicable.

${ }^{\mathrm{b}}$ Removed data 2SD outside of the mean from 1 participant that experienced a broken door knob.

${ }^{\mathrm{c}}$ Not assessed due to lower $\mathrm{N}$.

\section{Clinical Assessments}

Analyses of the WMFT using the average time to complete a task and the natural log transform both resulted in rejecting the null hypothesis. Only the average time to complete a task was reported. Participants improved performance from baseline to follow-up testing on both the Nine-Hole Peg Test $\left(\mathrm{t}_{15}=2.629\right.$, $P=.02)$ and the WMFT $\left(\mathrm{t}_{15}=2.675, P=.02\right)$. We explored how each task of the WMFT changed from baseline to follow-up. Tasks in which performance improved $(P<.05)$ included moving the hand from table to box (front), reaching and retrieving a 1-lb weight, and folding a towel. Tasks in which the decrease in time neared the $\alpha .05$ level include moving the weighted arm from the table to the box $(P=.07)$ and turning a key in a lock $(P=.08)$.

\section{Usability}

Examining usability of mRehab, the percentile rank on the SUS ranged from 60 to 97 . The average score was 81.7.

\section{Discussion}

\section{Principal Findings}

This study is novel in using scalable components, smartphones and 3D printed items, to create a portable rehabilitation system. Furthermore, extended in-home use of a system by end users without regular oversight is uncommon in research. Approximately $89 \%$ of participants (16/18) completed the 6-week mRehab home program. This demonstrates that participants can use mRehab in-home, with technical support provided as needed, to enhance upper limb function. This is encouraging as both individuals with stroke and their caregivers report feeling that more rehabilitation would be beneficial $[32,33]$. The combination of the in-home mRehab data set and laboratory-based clinical assessments provides insight into adherence, task-specific training, and generalized performance gains with mRehab home-based rehabilitation. 
For an exercise program to be effective there needs to be some degree of practice. The dosage of practice necessary to make gains is not well understood. A Cochrane review suggests that 30-60 minutes of rehabilitation per day, 5-7 days per week is effective [34]. Another review presented evidence that high-intensity and high repetition task-oriented and task-specific training is effective [35]. In this study, the average number of exercise days and repetitions was roughly half of the recommendation. The self-selected dosage was sufficient for improved performance in both mRehab and clinical measurements. We anticipated that individuals that practiced more would have larger improvements in the practiced mRehab activities. However, the data did not confirm this. It is possible that a larger cohort would have demonstrated a positive correlation. It is also possible that multiple mechanisms contributed to improvements with limited practice. Neurophysiology studies show that neuroplastic changes occur with learning a new skill and not after rote repetitive movement [36-38]. If participants can identify when repetitions become rote repetitive movement, they may reduce the dosage and more efficiently complete their home program. Task-specific training has shown to be more efficient compared with other nonspecific training approaches $[30,39]$. Besides, the addition of feedback has been shown to be effective [40].

There is an effort to better define and measure rehabilitation interventions to more fully understand what influences outcomes [41]. The data recorded by mRehab combined with performance changes on clinical assessments provide an opportunity to consider how exercise programs may impact performance on clinical outcome measures. We considered potential connections comparing tasks that decreased in time in both mRehab and WMFT. Time taken to complete all mRehab object transportation activities decreased. These activities would require adequate scapular, shoulder, elbow, wrist, and hand mobility and stability. Likewise, folding a towel in the WMFT would involve similar mobility and stability. In the WMFT, participants' scores improved for retrieving a 1-lb weight. While mRehab did not include progressive resistive training, repetitive task training has been shown to improve strength after stroke [42]. There were improvements on the Nine-Hole Peg Test, even though manipulation of objects using a pincer grasp was not part of the mRehab program. Participants did, however, demonstrate an improvement in performance of quick tap which requires fractionated finger movement. Taken together, it suggests that movement components trained within mRehab activities translate to other functional tasks. Having large-scale documentation of home exercise can lead to a better understanding of what form of exercise is most impactful on function.

A recent survey showed that clinicians perceive mRehab interventions as being important for supporting the function of patients at home and in the community, and improving adherence to home programs [43]. Therefore, it is necessary to perform research that examines how programs can be delivered at home. Other systems designed to improve upper limb function including custom hand-wrist orthosis and electrical stimulation, both designed to assist movement, or biofeedback to augment feedback during motor-based games have more commonly been assessed in clinical settings with the support of clinicians [44]. Tablet-based apps created to improve dexterity in the general population have been examined in individuals with stroke in a clinical setting, demonstrating that most individuals with stroke could use the system [12]. A gaming system designed for stroke used in a home-based setting, but included regular visits with clinicians, found similar results to this study, improvement in pre- to posttesting, but the correlation with practice was unremarkable. The percentage of days the participants used the gaming system ranged from $54 \%$ to $100 \%$ [25]. Overall, results from mHealth apps/systems appear promising, but much more research is needed to provide clinicians with the information they need to inform their decision making for mHealth home programs.

\section{Limitations}

While performance and usability of mRehab were assessed in laboratory prior to this study $[11,45]$, the extended in-home use revealed flaws in the system. About 63\% (10/16) of participants called to receive technical support and about $44 \%$ (7/16) of participants received home visits for assistance. The technical difficulties could have limited performance changes. In mRehab, the prehensile grip with supination/pronation activities did not demonstrate reduced times. It is possible that the difficulties with breakage of 3D door knobs and keys impeded performance improvements during training. Extended use of mRehab also demonstrated that the system did not work well for all individuals in the study. While inclusion and exclusion criteria were designed to select individuals that were a good fit with this intervention, 1 person did not complete the study. It is challenging to determine what combination of assessments will best predict adherence to mHealth-based programs. Further investigation is necessary to assure home programs are tailored to the individual's abilities.

Interestingly, when participants rated the usability at the end of the study, the average usability score for mRehab was 81.7. Modest technology assistance may have impacted the usability ratings. The use of technology in home programs is low [46]. It is possible that clinician's decision to use written home programs rather than technology is to eliminate the need for technology assistance. Not only is research necessary to create technology for rehabilitation, but also we must better understand how technology needs to be introduced and supported for successful use in self-managing long-term recovery.

\section{Conclusion}

The use of technology to improve home-programs and long-term recovery is promising. It can benefit both individuals with stroke in improving function and the field of rehabilitation in better understanding long-term recovery. 


\section{Acknowledgments}

This work was supported by the Eunice Kennedy Shriver National Institute of Child Health \& Human Development of the National Institutes of Health under award number R21 HD092243-01.

\section{Authors' Contributions}

JL and SB oversaw recruitment, training and clinical assessments, and wrote the first draft of the manuscript. WX, BC, and ZL oversaw app function and mRehab data collection. LC and HS oversaw usability of mRehab objects. LC conducted statistics. All authors provided suggestions or revisions to the manuscript.

\section{Conflicts of Interest}

None declared.

\section{References}

1. Shah S, Vanclay F, Cooper B. Efficiency, effectiveness, and duration of stroke rehabilitation. Stroke 1990 Feb;21(2):241-246. [doi: 10.1161/01.STR.21.2.241]

2. Langhorne P, Bernhardt J, Kwakkel G. Stroke rehabilitation. The Lancet 2011 May;377(9778):1693-1702. [doi: 10.1016/S0140-6736(11)60325-5]

3. Masiero S, Armani M, Rosati G. Upper-limb robot-assisted therapy in rehabilitation of acute stroke patients: Focused review and results of new randomized controlled trial. JRRD 2011;48(4):355-366. [doi: 10.1682/jrrd.2010.04.0063]

4. Miller KK, Porter RE, DeBaun-Sprague E, Van Puymbroeck M, Schmid AA. Exercise after Stroke: Patient Adherence and Beliefs after Discharge from Rehabilitation. Topics in Stroke Rehabilitation 2016 Jun 23;24(2):142-148. [doi:

10.1080/10749357.2016.1200292]

5. Fryer C, Luker J, McDonnell M, Hillier S. Self management programmes for quality of life in people with stroke. Cochrane Database Syst Rev 2016 Aug 22;2016(8):CD010442 [FREE Full text] [doi: 10.1002/14651858.CD010442.pub2] [Medline: 27545611]

6. Pollock A, St George B, Fenton M, Firkins L. Top 10 research priorities relating to life after stroke--consensus from stroke survivors, caregivers, and health professionals. Int J Stroke 2014 Apr 11;9(3):313-320. [doi:

10.1111/j.1747-4949.2012.00942.x] [Medline: 23227818]

7. Kwakkel G, Veerbeek JM, van Wegen EEH, Wolf SL. Constraint-induced movement therapy after stroke. The Lancet Neurology 2015 Feb;14(2):224-234 [FREE Full text] [doi: 10.1016/S1474-4422(14)70160-7]

8. Agostini M, Moja L, Banzi R, Pistotti V, Tonin P, Venneri A, et al. Telerehabilitation and recovery of motor function: a systematic review and meta-analysis. J Telemed Telecare 2015 Feb 22;21(4):202-213. [doi: 10.1177/1357633x15572201]

9. Hamine S, Gerth-Guyette E, Faulx D, Green BB, Ginsburg AS. Impact of mHealth chronic disease management on treatment adherence and patient outcomes: a systematic review. J Med Internet Res 2015 Feb 24;17(2):e52 [FREE Full text] [doi: 10.2196/jmir.3951] [Medline: 25803266]

10. Fu H, McMahon SK, Gross CR, Adam TJ, Wyman JF. Usability and clinical efficacy of diabetes mobile applications for adults with type 2 diabetes: A systematic review. Diabetes Res Clin Pract 2017 Sep;131:70-81. [doi:

10.1016/j.diabres.2017.06.016] [Medline: 28692830]

11. Li J, Zhang C, Li X, Zhang C. Patients' emotional bonding with MHealth apps: An attachment perspective on patients' use of MHealth applications. International Journal of Information Management 2020 Apr;51:102054. [doi: 10.1016/j.ijinfomgt.2019.102054]

12. Kizony R, Zeilig G, Dudkiewicz I, Schejter-Margalit T, Rand D. Tablet Apps and Dexterity. Journal of Neurologic Physical Therapy 2016;40(1):31-39. [doi: 10.1097/npt.0000000000000110]

13. Bhattacharjya S, Stafford MC, Cavuoto LA, Yang Z, Song C, Subryan H, et al. Harnessing smartphone technology and three dimensional printing to create a mobile rehabilitation system, mRehab: assessment of usability and consistency in measurement. J Neuroeng Rehabil 2019 Oct 29;16(1):127 [FREE Full text] [doi: 10.1186/s12984-019-0592-y] [Medline: 31665036]

14. Nussbaum R, Kelly C, Quinby E, Mac A, Parmanto B, Dicianno BE. Systematic Review of Mobile Health Applications in Rehabilitation. Arch Phys Med Rehabil 2019 Jan;100(1):115-127. [doi: 10.1016/j.apmr.2018.07.439] [Medline: $\underline{30171827]}$

15. Szturm T, Peters JF, Otto C, Kapadia N, Desai A. Task-specific rehabilitation of finger-hand function using interactive computer gaming. Arch Phys Med Rehabil 2008 Nov;89(11):2213-2217. [doi: 10.1016/j.apmr.2008.04.021] [Medline: $\underline{18996252]}$

16. Klamroth-Marganska V, Blanco J, Campen K, Curt A, Dietz V, Ettlin T, et al. Three-dimensional, task-specific robot therapy of the arm after stroke: a multicentre, parallel-group randomised trial. The Lancet Neurology 2014 Feb;13(2):159-166. [doi: 10.1016/s1474-4422(13)70305-3]

17. Pollock A, Farmer S, Brady M, Langhorne P, Mead G, Mehrholz J, et al. Interventions for improving upper limb function after stroke. Cochrane Database Syst Rev 2014 Nov 12;11(11):CD010820 [FREE Full text] [doi: 10.1002/14651858.CD010820.pub2] [Medline: 25387001] 
18. Hubbard IJ, Parsons MW, Neilson C, Carey LM. Task-specific training: evidence for and translation to clinical practice. Occup Ther Int 2009 Sep;16(3-4):175-189 [FREE Full text] [doi: 10.1002/oti.275] [Medline: 19504501]

19. Dobkin BH, Plummer-D'Amato P, Elashoff R, Lee J, SIRROWS Group. International randomized clinical trial, stroke inpatient rehabilitation with reinforcement of walking speed (SIRROWS), improves outcomes. Neurorehabil Neural Repair 2010;24(3):235-242 [FREE Full text] [doi: 10.1177/1545968309357558] [Medline: 20164411]

20. Cirstea C, Ptito A, Levin M. Feedback and Cognition in Arm Motor Skill Reacquisition After Stroke. Stroke 2006 May;37(5):1237-1242. [doi: 10.1161/01.str.0000217417.89347.63]

21. Cavuoto LA, Subryan H, Stafford M, Yang Z, Bhattacharjya S, Xu W, et al. Understanding User Requirements for the Design of a Home-Based Stroke Rehabilitation System. In: Proceedings of the Human Factors and Ergonomics Society Annual Meeting. 2018 Oct Presented at: 2018 Human Factors and Ergonomics Society (HFES) International Annual Meeting; 2018; Philadelphia, PA p. 1037-1041. [doi: 10.1177/1541931218621239]

22. Bobin M, Bimbard F, Boukallel M, Anastassova M, Ammi M. SpECTRUM: Smart ECosystem for sTRoke patient s Upper limbs Monitoring. Smart Health 2019 Aug;13:100066. [doi: 10.1016/j.smhl.2019.01.001]

23. Borghese NA, Pirovano M, Lanzi PL, Wüest S, de Bruin ED. Computational Intelligence and Game Design for Effective At-Home Stroke Rehabilitation. Games Health J 2013 Apr;2(2):81-88 [FREE Full text] [doi: 10.1089/g4h.2012.0073] [Medline: 24761321]

24. Llebaria G, Pagonabarraga J, Kulisevsky J, García-Sánchez C, Pascual-Sedano B, Gironell A, et al. Cut-off score of the Mattis Dementia Rating Scale for screening dementia in Parkinson's disease. Mov Disord 2008 Aug 15;23(11):1546-1550. [doi: 10.1002/mds.22173] [Medline: 18546326]

25. Slijper A, Svensson KE, Backlund P, Engström H, Sunnerhagen K. Computer game-based upper extremity training in the home environment in stroke persons: a single subject design. J Neuroeng Rehabil 2014 Mar 13;11(1):35 [FREE Full text] [doi: 10.1186/1743-0003-11-35] [Medline: 24625289]

26. Moss A, Nicholas M. Language Rehabilitation in Chronic Aphasia and Time Postonset. Stroke 2006 Dec;37(12):3043-3051. [doi: 10.1161/01.str.0000249427.74970.15]

27. Shumway-Cook A, Baldwin M, Polissar NL, Gruber W. Predicting the probability for falls in community-dwelling older adults. Phys Ther 1997 Aug 01;77(8):812-819. [doi: 10.1093/ptj/77.8.812] [Medline: 9256869]

28. Wolf S, Lecraw D, Barton L, Jann B. Forced use of hemiplegic upper extremities to reverse the effect of learned nonuse among chronic stroke and head-injured patients. Experimental Neurology 1989 May;104(2):125-132. [doi:

10.1016/s0014-4886(89)80005-6]

29. Oxford Grice K, Vogel KA, Le V, Mitchell A, Muniz S, Vollmer MA. Adult norms for a commercially available Nine Hole Peg Test for finger dexterity. Am J Occup Ther 2003 Sep 01;57(5):570-573. [doi: 10.5014/ajot.57.5.570] [Medline: $\underline{14527120]}$

30. Peres SC, Pham T, Phillips R. Validation of the System Usability Scale (SUS). In: Proceedings of the Human Factors and Ergonomics Society Annual Meeting. 2013 Sep 30 Presented at: 2018 Human Factors and Ergonomics Society (HFES) International Annual Meeting; 2018 October; Philadelphia, PA p. 192-196. [doi: 10.1177/1541931213571043]

31. Wolf SL, Thompson PA, Morris DM, Rose DK, Winstein CJ, Taub E, et al. The EXCITE trial: attributes of the Wolf Motor Function Test in patients with subacute stroke. Neurorehabil Neural Repair 2005 Sep 30;19(3):194-205. [doi: 10.1177/1545968305276663] [Medline: 16093410]

32. Tistad M, Tham K, von Koch L, Ytterberg C. Unfulfilled rehabilitation needs and dissatisfaction with care 12 months after a stroke: an explorative observational study. BMC Neurol 2012 Jun 18;12(1):40 [FREE Full text] [doi:

10.1186/1471-2377-12-40] [Medline: 22708545]

33. Duxbury S, Depaul V, Alderson M, Moreland J, Wilkins S. Individuals with stroke reporting unmet need for occupational therapy following discharge from hospital. Occup Ther Health Care 2012 Jan 23;26(1):16-32. [doi: 10.3109/07380577.2011.621514] [Medline: 23899105]

34. Pollock A, Baer G, Campbell P, Choo PL, Forster A, Morris J, et al. Physical rehabilitation approaches for the recovery of function and mobility following stroke. Cochrane Database Syst Rev 2014 Apr 22(4):CD001920 [FREE Full text] [doi: 10.1002/14651858.CD001920.pub3] [Medline: 24756870]

35. Veerbeek JM, van Wegen E, van Peppen R, van der Wees PJ, Hendriks E, Rietberg M, et al. What is the evidence for physical therapy poststroke? A systematic review and meta-analysis. PLoS One 2014 Feb;9(2):e87987 [FREE Full text] [doi: 10.1371/journal.pone.0087987] [Medline: 24505342]

36. Plautz EJ, Milliken GW, Nudo RJ. Effects of repetitive motor training on movement representations in adult squirrel monkeys: role of use versus learning. Neurobiol Learn Mem 2000 Jul;74(1):27-55. [doi: 10.1006/nlme.1999.3934] [Medline: $\underline{10873519]}$

37. Nudo RJ, Plautz EJ, Frost SB. Role of adaptive plasticity in recovery of function after damage to motor cortex. Muscle Nerve 2001 Aug;24(8):1000-1019. [doi: 10.1002/mus.1104] [Medline: 11439375]

38. Remple MS, Bruneau RM, VandenBerg PM, Goertzen C, Kleim JA. Sensitivity of cortical movement representations to motor experience: evidence that skill learning but not strength training induces cortical reorganization. Behavioural Brain Research 2001 Sep;123(2):133-141. [doi: 10.1016/s0166-4328(01)00199-1] 
39. Page SJ. Intensity Versus Task-Specificity After Stroke. American Journal of Physical Medicine \& Rehabilitation 2003;82(9):730-732. [doi: 10.1097/01.phm.0000078226.36000.a5]

40. Novak I. Effective home programme intervention for adults: a systematic review. Clin Rehabil 2011 Dec 10;25(12):1066-1085. [doi: 10.1177/0269215511410727] [Medline: 21831927]

41. Dijkers MP, Ferraro MK, Hart T, Packel A, Whyte J, Zanca JM. Toward a rehabilitation treatment taxonomy: summary of work in progress. Phys Ther 2014 Mar 01;94(3):319-321. [doi: 10.2522/ptj.20130999] [Medline: 24481596]

42. de Sousa DG, Harvey LA, Dorsch S, Glinsky JV. Interventions involving repetitive practice improve strength after stroke: a systematic review. J Physiother 2018 Oct;64(4):210-221 [FREE Full text] [doi: 10.1016/j.jphys.2018.08.004] [Medline: $\underline{30245180]}$

43. Morris J, Jones M, Thompson N, Wallace T, DeRuyter F. Clinician Perspectives on mRehab Interventions and Technologies for People with Disabilities in the United States: A National Survey. Int J Environ Res Public Health 2019 Oct 31;16(21):4220 [FREE Full text] [doi: 10.3390/ijerph16214220] [Medline: $\underline{\text { 31683536] }}$

44. Graham J. Technology for rehabilitating the upper limb after stroke: the hand. British Journal of Neuroscience Nursing 2014 Apr;10(Sup2):19-24. [doi: 10.12968/bjnn.2014.10.sup2.19]

45. Bhattacharjya S. Assessing the Functionality of a Portable Rehabilitation System Used for Self-Management of Upper Extremity Function by Individuals With Stroke. Am J Occup Ther 2018 Jul 01;72(4_Supplement_1):7211505134p1. [doi: 10.5014/ajot.2018.72s1-po6031]

46. Langan J, Subryan H, Nwogu I, Cavuoto L. Reported use of technology in stroke rehabilitation by physical and occupational therapists. Disabil Rehabil Assist Technol 2018 Oct 16;13(7):641-647. [doi: 10.1080/17483107.2017.1362043] [Medline: 28812386]

\author{
Abbreviations \\ BBS: Berg Balance Scale \\ MAS: Modified Ashworth Scale \\ MDRS: Mattis Dementia Rating Scale \\ mRehab: mobile Rehab \\ SUS: Systems Usability Scale \\ WMFT: Wolf Motor Function Test
}

\author{
Edited by G Eysenbach; submitted 28.04.20; peer-reviewed by L Tedesco Triccas, I Schiering; comments to author 20.05.20; revised \\ version received 04.06.20; accepted 25.06.20; published 22.07.20 \\ Please cite as: \\ Langan J, Bhattacharjya S, Subryan $H, X u W$, Chen B, Li Z, Cavuoto L \\ In-Home Rehabilitation Using a Smartphone App Coupled With 3D Printed Functional Objects: Single-Subject Design Study \\ JMIR Mhealth Uhealth 2020;8(7):e19582 \\ URL: http://mhealth.jmir.org/2020/7/e19582/ \\ doi: $10.2196 / 19582$ \\ PMID: 32706702
}

(CJeanne Langan, Sutanuka Bhattacharjya, Heamchand Subryan, Wenyao Xu, Baicheng Chen, Zhengxiong Li, Lora Cavuoto. Originally published in JMIR mHealth and uHealth (http://mhealth.jmir.org), 22.07.2020. This is an open-access article distributed under the terms of the Creative Commons Attribution License (https://creativecommons.org/licenses/by/4.0/), which permits unrestricted use, distribution, and reproduction in any medium, provided the original work, first published in JMIR mHealth and uHealth, is properly cited. The complete bibliographic information, a link to the original publication on http://mhealth.jmir.org/, as well as this copyright and license information must be included. 